\title{
Management of pre-eclampsia and its complications in the department of gynecology and obstetrics at Donka national hospital Conakry, Guinea
}

\author{
Boubacar Alpha Diallo*, Omou Hawa Bah, Ibrahima Conté, Ibrahima Sory Sow, \\ Ibrahima Koussi Bah, Souleymane Touré, Monique Lamah, Boubacar Poreko Diallo, \\ Mamy Ernest Lapko, Namory Keita, Mamadou Djoulré Baldé
}

University Gmal Agdel Nasser, Chair of Gynaecology and Obstetrics, Conakry, Guinéa

Received: 31 December 2019

Revised: 23 February 2020

Accepted: 02 March 2020

\section{*Correspondence:}

Dr. Boubacar Alpha Diallo,

E-mail: boubacardiallo2026@gmail.com

Copyright: (C) the author(s), publisher and licensee Medip Academy. This is an open-access article distributed under the terms of the Creative Commons Attribution Non-Commercial License, which permits unrestricted non-commercial use, distribution, and reproduction in any medium, provided the original work is properly cited.

\begin{abstract}
Background: Vascular-renal syndrome, also known as pre-eclampsia, is a condition specific to pregnancy, usually occurring in the last trimester of pregnancy. Pregnant women are sometimes at risk of unpredictable obstetrical complications such as: hemorrhage, kidney failure, HELLP syndrome, sometimes even brain damage requiring prompt care and multidisciplinary collaboration. Vascular-renal syndromes are the third leading cause of maternal death and also the world's leading cause of perinatal death. Objectives of this study were to analyse the management of vascular-renal syndromes. Calculate their frequency, describe the sociodemographic characteristics of patients, describe the clinical and biological signs of patients, evaluate the maternal-fetal prognosis.

Methods: The study was conducted in the department of obstetrics and gynecology of Donka National Hospital. It was a prospective, descriptive, cross-sectional, 6-month study from March $1^{\text {st }}$ to August $31^{\text {st }}$, 2015, of pregnant women with pre-eclampsia.

Results: The study included 217 cases of pre-eclampsia out of a total of 3054 patients, i.e. a proportion of 7.10\%. The proportion of pre-eclampsia was high in patients aged between 15 and 19 years, housewife, married, primary. The predisposing factors were primigestitis, obesity and twinkling. The clinic was dominated by headaches and visual disturbances. Severe preeclampsia in $78.49 \%$, eclampsia in $21.65 \%$ or simple hypertension in $1.75 \%$. Maternal and fetal complications were dominated by eclampsia $26.26 \%$, PPH (2.63\%), eclamptic coma (0.46\%), acute fetal distress $27.19 \%$, and fetal death in utero (11.40\%). In order to improve maternal and fetal prognosis it is necessary to provide multidisciplinary care, which unfortunately is not always available in our context.

Conclusions: Obstetric emergency is a frequent situation for which a better management would improve the maternal-fetal prognosis.
\end{abstract}

Keywords: Donka national hospital, Management, Maternal-fetal prognosis, Vascular-renal syndromes

\section{INTRODUCTION}

Preeclampsia is defined by the association of gestational hypertension (systolic blood pressure greater than or equal to $140 \mathrm{mmHg}$ and diastolic blood pressure greater than $90 \mathrm{mmHg}$ ) and proteinuria greater than or equal to $300 \mathrm{mg}$ per 24 hours after 20 weeks of amenorrhea (AS). It complicates 0.5 to $7 \%$ of pregnancies. It is a severe pregnancy pathology with persistent fetal mortality and morbidity and also maternal accidents such as 
retroplacental hematoma, HELLP syndrome and eclampsia. In the United States it is estimated that $15 \%$ of preterm births in the United States are due to preeclampsia $\left(82,000\right.$ births per year). ${ }^{1}$

In Africa the prevalence of pre-eclampsia averages $4 \%$ in the general population but can be as high as $18 \%$ in some ethnic groups. It is estimated that pre-eclampsia is responsible for 50,000 to 76,000 maternal deaths worldwide and 35,000 eclamptic seizures per year. ${ }^{1}$

This prevalence is $12.3 \%$ in Lomé, Togo, $17.36 \%$ in Bobo Djoulasso, Burkinafaso and $17.05 \%$ in Donka University Hospital in Guinea. ${ }^{2-4}$ In spite of medical advances, the pathophysiology of this pathology remains a theoretical problem whose exact mechanisms remain to be elucidated, even if the most credible hypothesis at the present time would be an abnormal placentation due to a deficit of trophoblastic invasion of the spiral arteries of the placental bed. ${ }^{1}$

Preeclampsia/eclampsia is a public health problem. It is one of the 3 leading causes of maternal mortality in the world and one of the leading factors in peri-natal death in the world. ${ }^{3}$

\section{METHODS}

The gynecology-obstetrics department of Donka National Hospital was used as a framework for the study. It was a cross-sectional, descriptive and analytical study with a duration of 6 months from March $1^{\text {st }}$ to August $31^{\text {st }}, 2015$. The minimum sample size was 217 patients.

\section{Inclusion criteria}

- All pregnant women with preeclampsia whose gestational age is $\geq 28 \mathrm{SA}$, whether or not followed in the ward and who delivered in the ward, were included.

\section{Exclusion criteria}

- Patients with less than 28 weeks of amenorrhea, those who were not managed on the ward.

Limitations of this study were the non-computing of the service data.

Before the study was carried out, we obtained the agreement of the administrative authorities of the service, the patients gave their consent to participate in the study, confidentiality was respected throughout the data collection procedure and the results were used for strictly scientific purposes.

\section{Statistical analysis}

Data were entered and analyzed using EPI INFO version 6 software. The statistical test used was Chi-square 2, with a significance level of $\mathrm{p}<0.05$. The statistical test used was the Chi-square 2 test, with a significance level of $\mathrm{p}<0.05$.

\section{RESULTS}

\section{Frequency}

Out of a total of 3054 deliveries we recorded a total of 217 cases of pre-eclampsia, either a proportion of $7.10 \%$.

Table 1: Socio-demographic characteristics and obstetrical history.

\begin{tabular}{|lll|}
\hline Age & Effective & $\%$ \\
\hline$<15$ & 2 & $0.88 \%$ \\
\hline $15-19$ & 53 & $24.56 \%$ \\
\hline $20-24$ & 42 & $19.30 \%$ \\
\hline $25-29$ & 50 & $22.81 \%$ \\
\hline $30-34$ & 32 & $14.91 \%$ \\
\hline $35-39$ & 27 & $12.28 \%$ \\
\hline $40-44$ & 6 & $2.63 \%$ \\
\hline$\geq 45$ & 6 & $2.63 \%$ \\
\hline Total & 217 & $100 \%$ \\
\hline Average age: $26.05 \pm 2.9$ years; extremes: 14 and & 45 years \\
\hline Marital situation & & \\
\hline Marrieds & 212 & $97.7 \%$ \\
\hline Singles & 5 & $2.30 \%$ \\
\hline Total & 217 & $100 \%$ \\
\hline Profession & & \\
\hline Housewives & 159 & $73.68 \%$ \\
\hline Pupils/students & 27 & $12.28 \%$ \\
\hline Liberal profession & 23 & $10.53 \%$ \\
\hline Official & 8 & $3.51 \%$ \\
\hline Total & 217 & $100 \%$ \\
\hline Parity & & $21.24 \%$ \\
\hline Nullipare & 86 & $100 \%$ \\
\hline Paucipar & 23 & \\
\hline Multipara & 46 & $10.62 \%$ \\
\hline Large multipara & 6 & \\
\hline Total & 217 & \\
\hline & & \\
\hline & & \\
\hline
\end{tabular}

Table 2: Patient distribution by reception mode.

\begin{tabular}{|lll|}
\hline Reception mode & Effective & $\%$ \\
\hline Coming from home & 142 & $65.49 \%$ \\
\hline Evacuated & 75 & $34.56 \%$ \\
\hline Total & 217 & $100 \%$ \\
\hline
\end{tabular}

Table 3: Distribution of patients by risk factors.

\begin{tabular}{|lll|}
\hline Risk factors & Effective & $\%$ \\
\hline Primigestite & 82 & $37.72 \%$ \\
\hline Obesity & 8 & $3.51 \%$ \\
\hline Twin pregnancy & 6 & $2.63 \%$ \\
\hline History of HTA & 2 & $0.88 \%$ \\
\hline
\end{tabular}


Age

the mean age of our patients was $26.05 \pm 2.9$ years with extremes of 14 and 41 years. Many of the women in the sample belonged to the 15-19 age group with a proportion of $24.56 \%$.

\section{Marital status}

during the study almost all the patients were married women, with a proportion of $98 \%$, which is explained by the fact that marriage is the legal framework for procreation in our country.

\section{Occupation}

The results of the study show that $73.68 \%$ were housewives.

\section{Parity}

More than $1 / 3^{\text {rd }}$ of the women $(39.82 \%)$ were nulliparous, followed by primiparous. The results show that slightly more than $1 / 3^{\text {rd }}$ of the women $(34.56 \%)$ in the sample were evacuees from the peripheral structures of the capital. Risk factors associated with pre-eclampsia were: primigest, obesity, twin pregnancy, and history of hypertension.

Table 4: Clinical signs and blood pressure figures on reception.

\begin{tabular}{|c|c|c|}
\hline Clinical signs & Effective & $\%$ \\
\hline Headache & 153 & $70.18 \%$ \\
\hline Visual disturbances & 147 & $67.54 \%$ \\
\hline Epigastric pain & 137 & $63.16 \%$ \\
\hline Oedemas & 72 & $33.33 \%$ \\
\hline Tonic-clonic crisis & 57 & $26.32 \%$ \\
\hline Convulsions & 44 & $20.18 \%$ \\
\hline Tinnitus & 17 & $7.89 \%$ \\
\hline $\begin{array}{l}\text { Others (physical asthenia; } \\
\text { fever; insomnia; vomiting) }\end{array}$ & 5 & $2.30 \%$ \\
\hline \multicolumn{3}{|l|}{ Systolic blood pressure } \\
\hline 140 & 2 & $0.88 \%$ \\
\hline $140-180$ & 177 & $81.58 \%$ \\
\hline $190-230$ & 32 & $14.91 \%$ \\
\hline 240 et plus & 8 & $2.63 \%$ \\
\hline Total & 217 & $100 \%$ \\
\hline \multicolumn{3}{|c|}{$\begin{array}{l}\text { Mean systolic blood pressure: } 170.18 \mathrm{mmHg} \text {; Extremes: } 140 \\
\text { and } 240 \mathrm{mmHg}\end{array}$} \\
\hline \multicolumn{3}{|c|}{ Diastolic blood pressure } \\
\hline$<100$ & 5 & $2.65 \%$ \\
\hline $100-120$ & 194 & $89.38 \%$ \\
\hline $130-150$ & 15 & $7.08 \%$ \\
\hline 160 et plus & 2 & $0.88 \%$ \\
\hline Total & 217 & $100 \%$ \\
\hline $\begin{array}{l}\text { Mean diastolic pressure: } 11 \\
\mathrm{mmHg} \text { and } 190 \mathrm{mmHg}\end{array}$ & $\mathrm{mmHg} ; \mathrm{E}$ & emes: 90 \\
\hline
\end{tabular}

The reasons for consultations were dominated by headaches $(70.18 \%)$, followed by visual disorders $(67.54 \%)$; epigastric pain $(63.16 \%)$, edema in $(33.33 \%)$, and tonic-clonic seizures $(24.56 \%)$.

Study found a mean systolic blood pressure of 170.18 $\mathrm{mmHg}$, with extremes of 140 and $240 \mathrm{mmHg}$ and a mean diastolic of $111.7 \mathrm{mmHg}$, with extremes of 90 and 190 mmHg. Thus, $81.58 \%$ of parturients had a systolic between 140 and $180 \mathrm{mmHg}$ and $89.38 \%$ had a diastolic between 100 and $120 \mathrm{mmHg}$.

Table 5: Breakdown of patients according to the results of the assessment at reception.

\begin{tabular}{|lll|}
\hline Proteinuria/24h in grams & Effective & $\%$ \\
\hline$<=2 \mathrm{~g}$ & 8 & $3.51 \%$ \\
\hline $3 \mathrm{~g}$ & 164 & $75.44 \%$ \\
\hline $4 \mathrm{~g}$ & 36 & $16.67 \%$ \\
\hline$>4 \mathrm{~g}$ & 9 & $4.39 \%$ \\
\hline Total & 217 & $100 \%$ \\
\hline Proteinuria/24 hours average: $3.1149 \mathrm{~g}$ Extremes: $0.3 \mathrm{~g}$ and $5 \mathrm{~g}$ \\
\hline Uremia (mmol/l) & & \\
\hline$<3$ & 1 & $3.60 \%$ \\
\hline $3.0-3.4$ & 2 & $21.63 \%$ \\
\hline $3.5-3.9$ & 1 & $39.63 \%$ \\
\hline$\geq 4.1$ & 1 & $35.11 \%$ \\
\hline Total & 217 & $100 \%$ \\
\hline Mean uremia: $3.99 \mathrm{mmol} / \mathrm{l} ;$ Extremes: 2.53 and $6.90 \mathrm{mmol} / \mathrm{l}$ \\
\hline Creatinuria $(\mathbf{m m o l} / \mathbf{l})$ & & \\
\hline$\leq 50$ & 0 & $0.00 \%$ \\
\hline $51-60$ & 2 & $0.91 \%$ \\
\hline $61-70$ & 81 & $37.27 \%$ \\
\hline$>70$ & 134 & $61.82 \%$ \\
\hline Total & 217 & $100 \%$ \\
\hline Medium create: $74.31 \mathrm{mmol} / \mathrm{l} ;$ Extremes: 59 and $89 \mathrm{mmol} / \mathrm{l}$ \\
\hline
\end{tabular}

Table 6: Breakdown of patients by diagnosis at reception and time of diagnosis.

\begin{tabular}{|lll|}
\hline Diagnostic & Effective & $\%$ \\
\hline Severe pre-eclampsia & 166 & $76.49 \%$ \\
\hline Eclampsia & 47 & $21.65 \%$ \\
\hline gestational hypertension & 4 & $1.75 \%$ \\
\hline Total & 217 & $100 \%$ \\
\hline Time of diagnosis & & \\
\hline Post-partum & 20 & $9.01 \%$ \\
\hline Term pregnancy & 160 & $73.87 \%$ \\
\hline During work & 37 & $17.12 \%$ \\
\hline Total & 217 & $100 \%$ \\
\hline
\end{tabular}

The mean 24-hour proteinuria was $3.49 \mathrm{~g}$ with extremes of $0.3 \mathrm{~g}$ and $5 \mathrm{~g}$.

A little more than $3 / 4$ of parturients, either $75.44 \%$, had proteinuria of $3 \mathrm{~g}$ per 24 hours. The average uricemia was $3.99 \mathrm{mmol} / \mathrm{l}$ with hyper uricemia $(\geq 4.1 \mathrm{mmol} / \mathrm{l}$ in $35.11 \%$. 


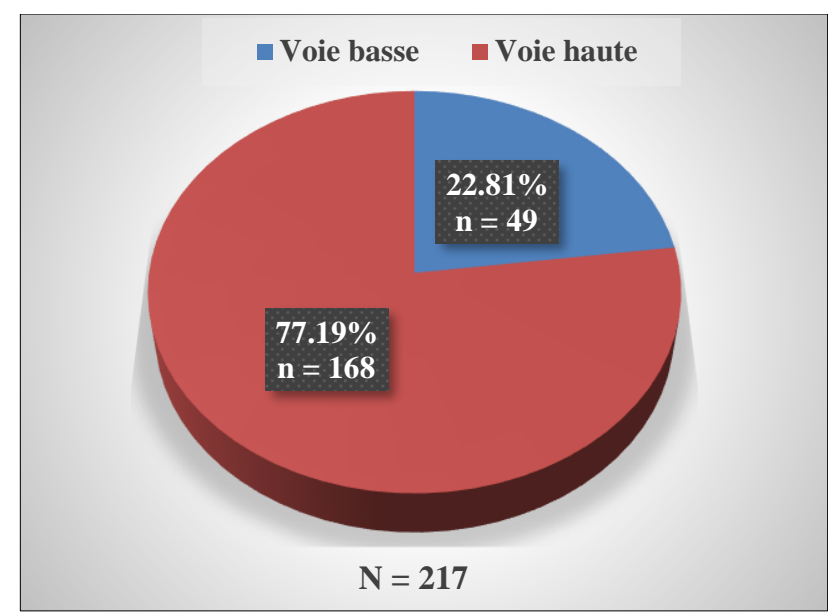

Figure 1: Distribution of patients by mode of delivery.

Table 7: Distribution of patients by maternal complications.

\begin{tabular}{|lll|}
\hline Maternal complication & Effective & $\%$ \\
\hline Eclampsia & 57 & $26.26 \%$ \\
\hline HRP & 6 & $2.63 \%$ \\
\hline Kidney failure & 2 & $0.88 \%$ \\
\hline eclamptic coma & 1 & $0.46 \%$ \\
\hline Death & 6 & $2.63 \%$ \\
\hline
\end{tabular}

Table 8: Patient distribution by fetal complications.

\begin{tabular}{|lll|}
\hline Fetal complication & Effective & $\%$ \\
\hline Wrong Apgar & 88 & $40.35 \%$ \\
\hline SFA & 59 & $27.19 \%$ \\
\hline Perinatal mortality & 25 & $11.40 \%$ \\
\hline
\end{tabular}

More than $3 / 4$ of women gave birth by caesarean section, $77.19 \%$. This could be explained by the severity of the clinical and paraclinical pictures at the reception desk on which the maternal-fetal prognosis depends

Maternal complications were dominated by eclampsia $26.26 \%$, retroplacental hematoma $(6.88 \%)$, renal failure $(0.88 \%)$, and eclamptic coma (0.46). We recorded 6 cases of death or $2.63 \%$. Fetal complications were dominated by a poor APGAR score in $40.35 \%$ requiring resuscitation, acute fetal suffering $27.19 \%$. Study recorded 25 cases of perinatal deaths, either $11.52 \%$.

\section{DISCUSSION}

\section{Overall frequency}

During the study period we collected 217 cases of preeclampsia out of a total of 3054 deliveries, either a proportion of $7.10 \%$. An identical proportion $(7.1 \%)$ of pre-eclampsia was found in Morocco by Magee LA et al. ${ }^{5}$ Slightly higher proportions of pre-eclampsia were found in Togo (12.3\%), Nigeria (10.2\%), Pakistan (9.3\%) and Mozambique (10.9\%). , $^{2,6}$

\section{Maternal age}

The mean age of our patients was $26.05 \pm 2.9$ years with extremes of 14 and 41 years. Many of the women in the sample belonged to the 15-19 age group with a proportion of $24.56 \%$ (Table 1 ).

An identical mean age of 26.37 years was found in Bobodjoulasso in Burkina faso by Diallo JW et al with extremes of 15 and 40 years. The most represented age groups in their study were those aged 26 to 30 years with $29.1 \%$ of cases and those aged 15 to 20 years with $25.2 \%{ }^{3}$ In Lomé, Togo Baragou $\mathrm{S}$ et al found a higher mean age of $30 \pm 7$ years, with extremes of 15 and 44 years, and preeclampsia was more frequent (50\%) among 30-39 year olds. ${ }^{2}$ In Keita $\mathrm{M}$ et al found a mean age lower than ours of $20 \pm 4$ years. $^{7}$

\section{Marital status}

During the study almost all the patients were married women, with a proportion of $98 \%$, which is explained by the fact that marriage is the legal framework for procreation in our country (Table 1).

\section{Occupation}

The results of the study show that $73.68 \%$ were housewives (Table 1). The high proportion of housewives was reported in several studies such as that of Baragou SM et al, in Lomé, Togo (33.3\%); and that of SEPOU A et al, in the Central African Republic (52.8\%). ${ }^{2,8}$ The low socioeconomic level, early marriages combined with low contraceptive use could explain our result.

\section{Parity}

More than $1 / 3^{\text {rd }}$ of the women $(39.82 \%)$ were nulliparous, followed by Primiparous $25.66 \%$ (Table 1). This result is comparable to several data in the African literature. Primiparity was cited as a risk factor by Diouf AA et al in Dakar, Senegal, by Keita $\mathrm{M}$ et al in Mali respectively $(58.1 \%)$ and $(65.8 \%))^{7,9}$

\section{Mode of patient admission}

The results show that slightly more than $1 / 3^{\text {rd }}$ of the women $(34.56 \%)$ in the sample were evacuees from the peripheral structures of the capital (Table 2). Higher evacuation rates were noted in several African studies: at the CHU-Yalgado in Ouagadougou, Ouattara et al, reported $72.4 \%$ of referrals, and in Senegal Djouf AA et al, reported $(82.3 \%)$ evacuations for eclampsia. ${ }^{9,10}$

\section{Risk factors}

Risk factors associated with pre-eclampsia were: primigravida, obesity, twin pregnancy, and history of hypertension. In Cameroon Mboudou et et al found that the risk factors associated with eclampsia were 
dominated by age less than 20 years, primigravidity, baseline, and oliguria (Table 3$).{ }^{11}$

\section{Distribution of patients according to clinical signs at reception}

The reasons for consultations were dominated by headaches $(70.18 \%)$, followed by visual disorders $(67.54 \%)$; epigastric pain $(63.16 \%)$, edema in $(33.33 \%)$, and tonic-clonic seizures $(24.56 \%)$ (Table 4). An almost identical clinical picture was found in Bobo Djoulasso by Diallo JW et al, general altered state or a state of coma, $(25.3 \%)$, edema of the lower limbs $(76.4 \%)$ and visual disorders in $33 \%$ of cases. ${ }^{3}$

\section{Blood pressure}

Study found a mean systolic blood pressure of 170.18 $\mathrm{mmHg}$, with extremes of 140 and $240 \mathrm{mmHg}$ and a mean diastolic of $111.7 \mathrm{mmHg}$, with extremes of 90 and 190 mmHg. Thus, $81.58 \%$ of parturients had a systolic between 140 and $180 \mathrm{mmHg}$ and $89.38 \%$ had a diastolic between 100 and $120 \mathrm{mmHg}$ (Table 4). Study data are comparable to those reported in the study by Baragou $\mathrm{S}$ et al in Lomé where the mean systolic BP was 182.5 $\mathrm{mmHg}$, with a maximum value of $260 \mathrm{mmHg}$, a mean diastolic BP of $114.7 \mathrm{mmHg}$ and a maximum value of $150 \mathrm{mmHg}^{2}$

\section{Biological balance sheet}

The mean 24-hour proteinuria was $3.49 \mathrm{~g}$ with extremes of $0.3 \mathrm{~g}$ and $5 \mathrm{~g}$. A little more than $34^{\text {th }}$ of parturients, either $75.44 \%$, had proteinuria of $3 \mathrm{~g}$ per 24 hours. The average uricemia was $3.99 \mathrm{mmol} / 1$ with hyper uricemia $(\geq$ $4.1 \mathrm{mmol} / \mathrm{l}$ in $35.11 \%$, (Table 5).

\section{Breakdown of patients by diagnosis at reception and time of diagnosis}

The clinical and paraclinical data allowed us to diagnose severe preeclampsia in $76.49 \%$ and eclampsia in $21.65 \%$. These diagnoses were made at term in $73.87 \%$ of cases during labour and $9.01 \%$ of cases during postpartum (Table 6). Several elevations of BP during pregnancy are described as those of Mboudou et al in Cameroon who reported $77.88 \%$ of cases of preeclampsia and $15.38 \%$ of gestational hypertension. ${ }^{11}$ In Keita $\mathrm{M}$, et al, reported $70.6 \%$ preeclampsia and $29.4 \%$ eclampsia. $^{7}$

\section{Mode of delivery}

More than $34^{\text {th }}$ of women gave birth by cesarean section, $77.19 \%$. This could be explained by the severity of the clinical and paraclinical pictures at the reception desk on which the maternal-fetal prognosis depends (Figure 1). Our result is comparable to the $75.5 \%$ of caesarean sections reported in Senegal by Djouf AA et al, but a lower proportion of caesarean section deliveries (41.13\%) was reported in Mali by Keita $\mathrm{M}$ et al. ${ }^{7,9}$ In Ethiopia
Netsanet AA et al describe that only $1.3 \%$ of their patients delivered by caesarean section. ${ }^{12}$

\section{Maternal prognosis}

Maternal complications were dominated by eclampsia $26.26 \%$, retroplacental hematoma $(6.88 \%)$, renal failure $(0.88 \%)$, and eclamptic coma (0.46). We recorded 6 cases of death or $2.63 \%$ (Table 7). In Algeria, Kichou B et al report $28.7 \%$ of complications, including 5 deaths, i.e. $1.98 \%$ of maternal deaths. ${ }^{13}$

\section{Fetal prognosis}

Fetal complications were dominated by a poor Apgar score in $40.35 \%$ requiring resuscitation, acute fetal suffering $27.19 \%$. Study recorded 25 cases of perinatal deaths, i.e. $11.52 \%$ (Table 8). In Algeria, Kichou B et al, report $58.2 \%$ prematurity, $49.7 \%$ intrauterine growth retardation, and $6.7 \%$ fetal death. ${ }^{13}$ In Dakar (Senegal) Boiro D et al, found in 141 hospitalized neonates of preeclamptic mothers that neonatal complications were dominated by: prematurity 93 cases (65.93\%), intrauterine growth retardation 98 cases $(69.50 \%)$, respiratory distress 58 cases $(41.13 \%)$, and perinatal asphyxia 8 cases $(5.6 \%) .{ }^{14}$

\section{CONCLUSION}

The incidence of preeclampsia was $7.10 \%$. Predisposing factors were mainly predigesting, obesity and twinkling.

The clinic was dominated by high blood pressure, headache and visual disturbances. The main diagnoses selected were severe preeclampsia in $76.49 \%$, and eclampsia in $21.65 \%$. More than $34^{\text {th }}$ of women gave birth by caesarean section, $77.194 \%$. The main maternal and fetal complications found in this study were eclampsia in $26.26 \%$, retro placental hematoma $(6.88 \%)$, renal failure $(0.88 \%)$, poor Apgar score in $40.35 \%$, acute fetal distress in $27.19 \%$. We recorded 6 cases of maternal deaths or $2.63 \%$ and 25 cases of perinatal deaths or $11.52 \%$.

\section{Funding: No funding sources \\ Conflict of interest: None declared}

Ethical approval: The study was approved by the Institutional Ethics Committee

\section{REFERENCES}

1. Winer N, Tsasaris V. State of knowledge: therapeutic management of preeclampsia. J Gynecol Obstet Reprod Biol. 2008;37(1):5-15.

2. Baragou SMP, Goeh-Akue E, Afassinou YM. Hypertension and pregnancy in Lomé (sub-Saharan Africa): epidemiological, diagnostic and risk factor aspects. Ann Cardiol Angeiol. 2014;63(3):145-50.

3. Wenceslas DJ, Méda N, Ahnoux-Zabsonré A, Ouattara S, Yanogo A, Tougouma SJB, et al. Manifestations during severe pre-eclampsia or 
eclampsia at the University Hospital Center Sourô Sanou de Bobo Dioulasso. Pan Afr Med J. 2015;21:1-8.

4. Bah AO, Diallo MH, Diallo AAS, Keita N, Diallo MS. Arterial hypertension and pregnancy: epidemiological aspects and risk factors; Black African Med. 2000;47(10):422-5.

5. Benfateh $\mathrm{M}$, Cissoko $\mathrm{S}$, Boufettal $\mathrm{H}$, Feige JJ, Samouh N, Aboussaouira T, et al. Risk factors and poor prognostic factors of preeclampsia in Ibn Rochd University Hospital of Casablanca: about 401 preeclamptic cases. Pan Afr Med J. 2018;31.

6. Magee LA, Sharma S, Nathan HL, Adetoro OO, Bellad MB, Goudar S, et al. The incidence of pregnancy hypertension in India, Pakistan, Mozambique, and Nigeria: a prospective populationlevel analysis. PLoS Med. 2019;16(4):e1002783.

7. Keïta M, Diallo BM, Samaké BM, Fomba S, Dicko $H$, Goïta D, et al. Epidemiology and maternal prognosis of eclampsia in the intensive care unit at the University Hospital of Point G, Bamako. Le Mali Med. 2016;31(2):1-9.

8. Sepou A, Goddot M, Ngbale R, Gaunefet CE, Domande-Modanga Z, Fandema E. Evolution of the frequency and problems related to medical evacuations to the gynaecology and obstetrics department of the Bangui Community Hospital. Clin Mother Child Health. 2009;6:1007-12.

9. Diouf AA, Diallo M, Mbaye M, Sarr SD, FayeDiémé ME, Moreau JC, et al. Epidemiological profile and management of eclampsia in Senegal: about 62 cases. Pan Afr Med J. 2013;16:83.
10. Ouattara A, Ouédraogo CM, Ouédraogo A, Kain DP, Zamané H, Kiemtoré S, et al. L'éclampsie au CHUYalgado de Ouagadougou (Burkina Faso) du 1 er avril 2013 au 31 mars 2014. Bulletin de la Société de Pathol Exotique. 2015;108(5):316-23.

11. Mboudou ET, Foumane P, Priso EB, Dohbit J, Minkande JZ, Nkengafac WM, et al. Hypertension of during pregnancy: Clinical and epidemiological aspects at the Gyneco-Obstetric and Pediatric Hospital of Yaounde, Cameroon. Clin Mother Child Health. 2009;6(2):1087-93.

12. Asseffa NA. Perinatal outcomes of hypertensive disorders in pregnancy at a referral hospital, Southern Ethiopia. PLoS One. 2019;14:1-10.

13. Kichou B, Henine N, Kichou L, Benbouabdellah M. Epidemiology of preeclampsia in the region of Tiziouzou (Algeria). Ann Cardiol Angelol. 2015;64(3):164-8.

14. Boiro DPM, Fayeb M, Gueyea A, Sowa A, Dieng AA, Ndongoc L, et al. Preeclampsia: what complications in the newborn? J Pediatr Childcare. 2018;31(6):282-6.

Cite this article as: Diallo BA, Bah $\mathrm{OH}$, Conté I, Sow IS, Bah IK, Touré S, et al. Management of preeclampsia and its complications in the department of gynecology and obstetrics at Donka national hospital Conakry, Guinea. Int J Reprod Contracept Obstet Gynecol 2020;9:1858-63. 